\title{
Environmental impact on chemical/oil spill in the Persian Gulf
}

\author{
P. C. Chu ${ }^{1}$, C. L. Williams ${ }^{1}$, T. Clem ${ }^{1}$, S. D. Haeger ${ }^{2}$ \& M. Ward ${ }^{3}$ \\ ${ }^{I}$ Naval Ocean Analysis and Prediction Laboratory, \\ Naval Postgraduate School, Monterey, California, USA \\ ${ }^{2}$ Naval Oceanographic Office, Stennis Space Center, Mississippi, USA \\ ${ }^{3}$ Applied Science Associates, Inc., Narragansett, Rhode Island, USA
}

\begin{abstract}
An attack on, or chemical spill near Iraq's oil terminals could have disastrous effects on the economy. The impact from chemical spill is highly dependent upon environmental conditions that can either adversely affect continued operations or hinder the safety of personnel. Operational planners' ability to create legitimate scenarios to train and combat these situations is the key to continued safe operation of the terminals. To accomplish this, planners must understand the impacts of using climatology versus near real-time data in the evaluation of the scenarios. This study demonstrates great impact of using near real-time environmental conditions, provided by a coupled ocean-atmospheric circulation-chemical model with data assimilation scheme, for operational planners.
\end{abstract}

Keywords: chemical spill, oil spill, Persian Gulf, Strait of Hormuz, COAMPS, NCOM, HPAC, CHEMMAP, OILMAP.

\section{Introduction}

The Persian Gulf, also known as the Arabian Gulf, is a semi-enclosed marginal sea connected with the Indian Ocean through the Strait of Hormuz with the major axis tending in the NW-SE direction (Fig. 1). The Persian Gulf is approximately $990 \mathrm{~km}$ long; the maximum width is about $338 \mathrm{~km}$. The estimated surface area and volume of the gulf are around $239,000 \mathrm{~km}^{2}$ and $8,630 \mathrm{~km}^{3}$, respectively, which correspond to a mean depth of close to $36 \mathrm{~m}$. The maximum depth is around $100 \mathrm{~m}$ near the Strait of Hormuz, with the Gulf of Oman (GOO) 
being much deeper. The major axis of the basin separates a relatively deeper channel near the Iranian coast from the shallow Persian shelf that slops gently towards the axis.
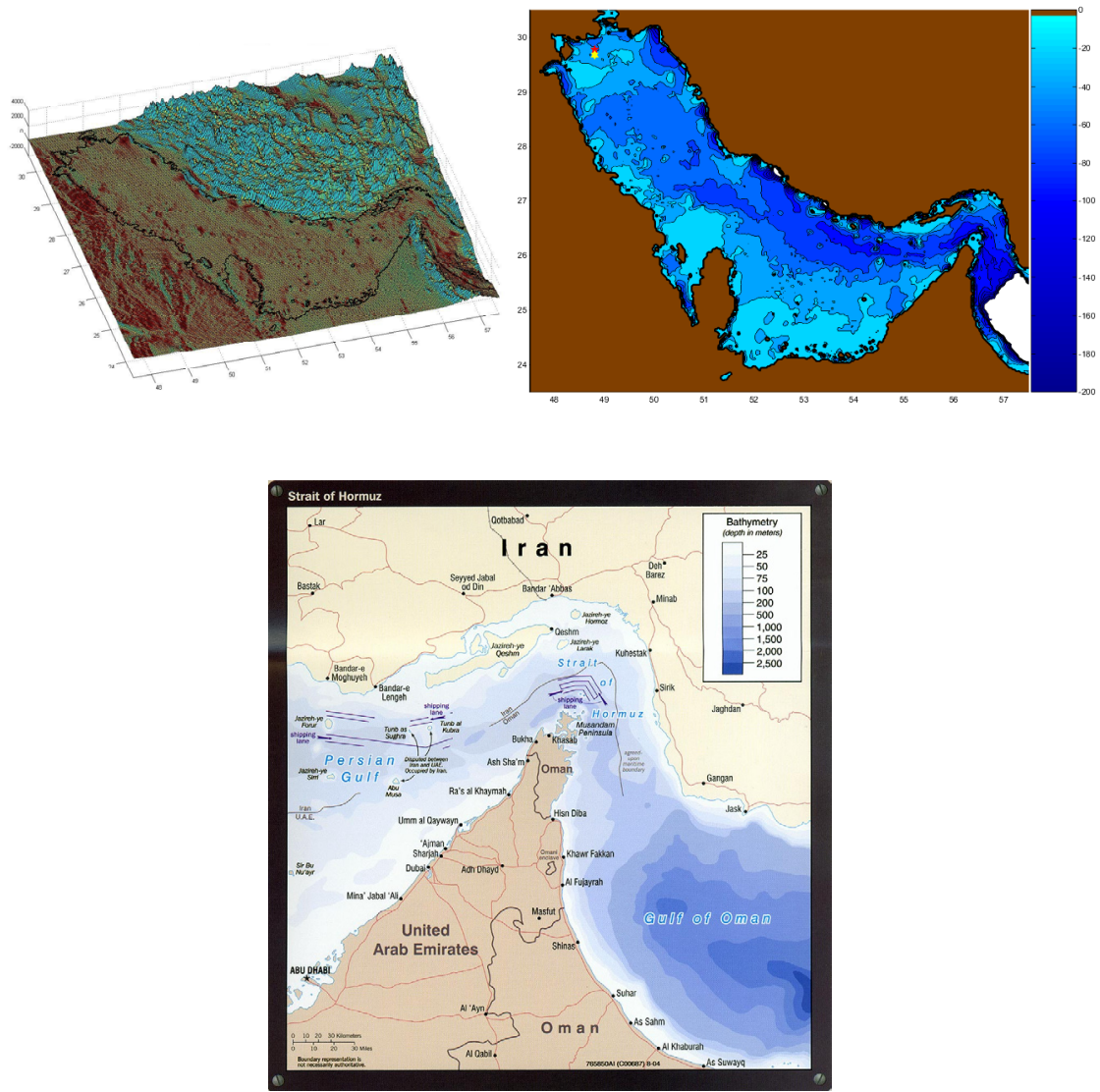

Figure 1: Topography and bathymetry in the Persian Gulf.

Orographic influences on the atmospheric circulation are very significant due to the high mountains bordering much of the coastline in this region (Figure 2). The Zagros Mountains of Iran and the Jebel al Akhdar range in northern Oman play an important role in focusing the winds over the region. The Persian Gulf is characterized by northwesterly or westerly winds throughout the year (U.S. Hydrographic Office, 1960). The summer winds are mild and continuous. In contrast the winds in winter are often associated with synoptic weather systems, and breaks out suddenly and violently (Reynolds [1]).

Due to its shallow nature, the Persian Gulf appears to be influenced by winds and surface thermohaline fluxes. The persistent southward wind stress, at least in the northern half of the Gulf, appears to set up coastal current regimes along both the Saudi (downwelling) and Iranian (upwelling) coasts. A persistent thermal 
front across the Persian Gulf about the latitude of Qatar appears related to the thermohaline exchange through the Strait of Hormuz ( $\mathrm{SOH}$ ) and splits the Persian Gulf into two regimes. The winds and currents in the Gulf of Oman are influenced by the southwest monsoon. This influence continues through the Straights of Hormuz and into the eastern regime.

It is in this uneasy environment that approximately one-third of the world's supply of oil is provided. According to a report from the Energy Information Administration, roughly $90 \%$ of the oil leaving the Gulf, accounting for about two-fifths of the world's free traded oil, left via tankers transiting the SOH (Kreil [2]). Interestingly, the $\mathrm{SOH}$ is a natural choke point narrowing to just $56 \mathrm{~km} \mathrm{(34}$ miles) across with two mile wide transit lanes separated by a two mile wide buffer (Fig. 1). On 24 January 2000, Honduran-flagged cargo vessel Al Jazya 1 sank 4 miles east of Abu Dhabi's coast, laden with 980 tons of fuel oil. This vessel sank in bad weather. Also, on 6 April 2001, the Iraqi fuel tanker Zainab, suspected of smuggling around 1,300 tons of fuel oil from Iraq, ran into trouble on its way to a holding area in international waters. It left an oil spill with a 12 $\mathrm{km}$ radius which reached the reserved island of Sir Bou Neair, about 70 nautical miles off the coast of the Emirate of Sharjah Understanding the oceanic effects on potential oil spills could mean the difference for a faster recovery from an incident at this choke point. The faster the clean up, the faster shipping and maritime patrol can resume. In this study, we take environmental impact on oil spill in the $\mathrm{SOH}$ as an example for illustration.

\section{Coupled ocean-atmospheric circulation-chemical model}

This study utilizes ocean-atmospheric physical-chemical models to predict mine drifting and oil spill dispersion. This system contains four major parts: (1) the atmospheric part of the Navy's Coupled Ocean Atmospheric Mesoscale Prediction System (COAMPS), (2) the Navy's Coastal Ocean Model (NCOM), (3) the Defense Threat Reduction Agency (DTRA) Hazardous Prediction and Assessment Capability (HPAC) Tool, and (4) the ocean chemical dispersion model, CHEMMAP ${ }^{\mathrm{TM}}$. The atmospheric part of COAMPS drives NCOM and HPAC. The NCOM drives CHEMMAP ${ }^{\mathrm{TM}}$.

\subsection{COAMPS}

The atmospheric part of COAMPS (Hodur [3]) is comprised of the nonhydrostatic, fully compressible equations of atmospheric motion, thermodynamics, and continuity. The transformation of the vertical coordinate is applied to map the lowest coordinate surface to an irregular lower boundary

$$
\sigma=z_{\text {top }}\left(\frac{z-z_{s f c}}{z_{t o p}-z_{s f c}}\right),
$$

where $z_{\text {top }}$ is the depth of the model domain and $z_{s f c}$ is the height of the topography. Both the horizontal and vertical grids in the forecast model are staggered. The horizontal grid uses the Arakawa-Lamb C-staggering scheme. 
COAMPS uses a level 2.5 scheme (Mellor and Yamada [4]) that solves both a prognostic equation for turbulent kinetic energy (TKE) and diagnostic equations for second-moment quantities such as primarily fluxes of heat, moisture, and momentum. The surface layer parameterization follows the Louis (1979) scheme, which uses polynomial functions of the bulk Richardson number to directly compute surface sensible heat flux, surface latent heat flux, and surface drag.

Although the equations are solved on a staggered C-grid, the atmospheric data assimilation using COAMPS is performed on the Arakawa-Lamb A-grid (i.e., no grid staggering). The bicubic spline interpolation is used to interpolate the analyzed fields to the $\mathrm{C}$-grid within the forecast model code. The COAMPS analysis is based on the multivariate optimum interpolation (MVOI) analysis scheme. Observational data include the following data types: (1) Radiosonde, (2) Pibal, (3) Surface land, (4) Surface marine, (5) Aircraft, and (6) Satellites (including SSM/I, Scatterometer, Sea Surface Temperature, and QUIKScat).

\section{$2.2 \mathrm{NCOM}$}

NCOM is built based on the Princeton Ocean Model (POM, Blumberg and Mellor, 1987) with the main differences in data assimilation. The principal attributes of the model are as follows: (1) it contains an imbedded second moment turbulence closure sub-model to provide vertical mixing coefficients. (2) It is a sigma coordinate model in that the vertical coordinate is scaled on the water column depth. (3) The horizontal grid uses curvilinear orthogonal coordinates and C-grid. (4) The horizontal time differencing is explicit whereas the vertical differencing is implicit. The latter eliminates time constraints for the vertical coordinate and permits the use of fine vertical resolution in the surface and bottom boundary layers. (5) Complete thermodynamics have been implemented. The basic equations have been cast in a bottom following, sigma coordinate system,

$$
x^{*}=x, y^{*}=y, \sigma=\frac{z-\eta}{H+\eta}, t^{*}=t,
$$

where $(x, y, z)$ are the conventional Cartesian coordinates; where $H(x, y)$ is the bottom topography and $\eta(x, y, t)$ is the surface elevation. The reader is referred to Blumberg and Mellor (1987) for a derivation of the basic equations in sigma coordinate system.

\subsection{HPAC}

HPAC It is used to accurately predict the effects of hazardous material releases into the atmosphere and its impact on civilian and military populations (Sykes [5]). The system uses integrated source terms, high-resolution weather forecasts and particulate transport analyses to model hazard areas produced by military or terrorist incidents and industrial accidents. The HPAC system can also help answer the question, "How good is the prediction?" by providing probabilistic calculations. The hazard area feature estimates the weather uncertainty and 
turbulence effects on possible plume trajectories and calculates the areas of hazard impact and the degree of confidence of the prediction. The SCIPUFF model is the atmospheric transport empirical model used in HPAC.

SCIPUFF uses a Gaussian puff representation for the concentration field of a dispersing contaminant. A three-dimensional Gaussian is completely described by its spatial integral moments up to second-order, and can be written in the form

$$
c(x)=\frac{Q}{(2 \pi)^{3 / 2}(\operatorname{Det}(\sigma))^{1 / 2}} \exp \left[-\frac{1}{2} \sigma_{i j}^{-1}\left(x_{i}-\overline{x_{i}}\right)\left(x_{j}-\overline{x_{j}}\right)\right] .
$$

For atmospheric dispersion problems, one must also consider the effects of the ground surface and the capping inversion at the top of the planetary boundary layer, which are usually represented as reflective surfaces. The specific Gaussian variation (4) applies to an individual puff, but in general the local concentration field will be composed of a sum of contributions from a number of such puffs.

\subsection{CHEMMAP/OILMAP ${ }^{\mathrm{TM}}$}

Applied Science Associates (ASA) has been developed a chemical/oil spill model, CHEMMAP/OILMAP ${ }^{\mathrm{TM}}$, to predict the trajectory and fate of a wide variety of chemical products, including floating, sinking, soluble and insoluble chemicals and product mixtures. CHEMMAP ${ }^{\mathrm{TM}}$ simulated a number of processes including: (1) slick spreading, transport, and entrainment of floating materials, (2) transport of dissolved and particulate materials in three dimensions, (3) evaporation and volatilization, (4) dissolution and adsorption, (5) sedimentation and re-suspension, (6) and degradation. The model uses physical-chemical properties to predict the fate of a chemical spill. These include density, vapor pressure, water solubility, environmental degradation rates, adsorbed/dissolved partitioning coefficients $\left(K_{O W}, K_{O C}\right)$, viscosity, and surface tension (Chu et al. $[6,7])$.

For surface slicks, the model estimates surface spreading, slick transport, entrainment into the water column, and evaporation, to determine trajectory and fate at the surface. Spreading is simulated using the algorithm of Fay (1971). The fates model computes, in space and time, the following: (1) area covered by surface slicks, (2) radius and thickness of surface slicks, (3) total concentration in the water column, (4) dissolved concentration in the water column, (5) area and length of shorelines contaminated, (6) mass per unit area on the shorelines. These model output data are mapped by the user interface in an animated display.

\section{Spill site locations}

Either a terrorist from any number of organizations currently in play, or accidents on oil shipping through the Strait of Hormuz, will cause severe oil spill and hamper the movement of shipping, civilian and military, through the $\mathrm{SOH}$. We choose four particular locations on both the eastern and western legs of the $\mathrm{SOH}$ in or near the transit lanes. Additionally, two locations near the tip of the 
Musandam Peninsula as the shipping lanes are tightest through that area. This covered most of the region's flow regimes and gave a wide look to possible outcomes. Fig. 2 shows the locations of the four sites chosen. Sites 1 and 2 are at the tip of the peninsula, Site 3 is on the eastern leg towards the GOO, and Site 4 is on the western leg. These sites are close to the grid points of COAMPS and NCOM (Table 1).

\section{Winds and ocean currents}

The ocean-atmospheric circulation models are running operationally in the Fleet Numerical Meteorology and Oceanography Center (for COAMPS) located in Monterey California and in the Naval Oceanographic Office (for NCOM) located at the Stennis Space Center in Mississippi with a $24 \mathrm{hr}$ hindcast and $48 \mathrm{hr}$ forecast. We analyze the data of the surface winds and ocean currents (at $5 \mathrm{~m}$ depth) for the area from $23.5^{\circ} \mathrm{N}$ to $30.5^{\circ} \mathrm{N}$ and $47.5^{\circ} \mathrm{E}$ to $57.5^{\circ} \mathrm{E}$ from the COAMPS-NCOM. The horizontal resolution of the operational model is $2 \mathrm{~km}$. The data with I hr resolution (from February 1 through July 31, 2006) are used for the analysis. Here, we take the $\mathrm{SOH}$ as an example for illustration. Four patterns of variability in winds and ocean currents are found. They are: (1) low winds/low currents, (2) low winds/high currents, (3) high winds/low currents, and (4) high winds/high currents.

Each combination sought to establish extremes encountered in the environment to highlight differences from climatology. Time series of wind and current at all four of the selected spill sites are constructed and then compared to come up with the combinations necessary for evaluation. Each combination of high and low for wind and current was sought at each spill site to cover a five day period optimally. We only show the environments for the site-1 (Fig. 3).

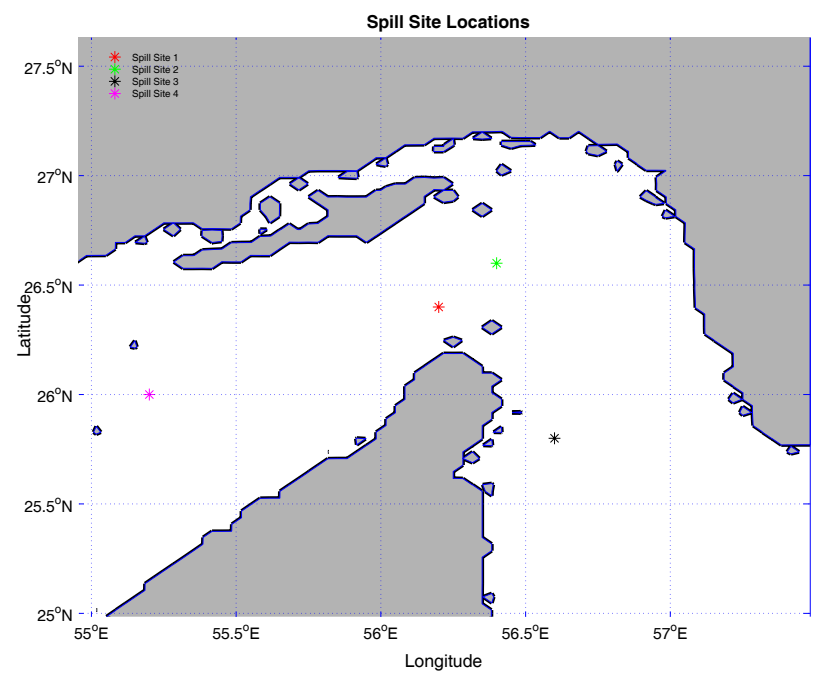

Figure 2: $\quad$ Spill site locations. 
Table 1: $\quad$ Nearest grid points of COAMPS and NCOM for the spill sites.

\begin{tabular}{|c|c|c|c|c|}
\hline \multirow{2}{*}{ Spill Site } & \multicolumn{2}{|c|}{ SWAFS } & \multicolumn{2}{c|}{$\underline{\text { COAMPS }}$} \\
\cline { 2 - 5 } & Lat (deg N) & Lon (deg E) & Lat (deg N) & Lon (deg E) \\
\hline $\mathbf{1}$ & 26.395 & 56.157 & 26.4 & 56.2 \\
\hline $\mathbf{2}$ & 26.604 & 56.401 & 26.6 & 56.4 \\
\hline $\mathbf{3}$ & 25.804 & 56.601 & 25.8 & 56.6 \\
\hline $\mathbf{4}$ & 25.995 & 55.201 & 26.0 & 55.2 \\
\hline
\end{tabular}

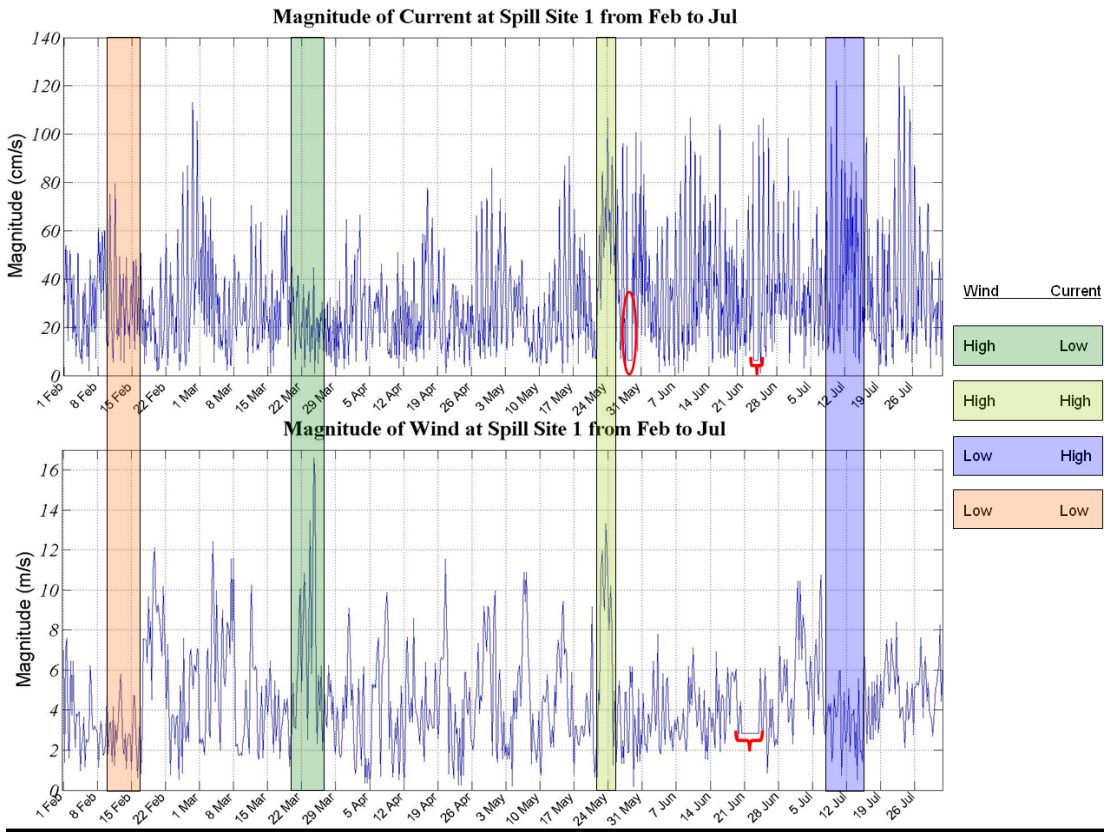

Figure 3: $\quad$ Time series of ocean surface current speed (upper panel) and wind speed (lower panel) at site-1 predicted by NCOM and COAMPS models. Four types (low high current winds/low currents, low winds/high currents, high winds/low currents, and high winds/high currents) are identified.

Low winds and currents occurrences occurred quite a few times at all spill sites. For ease of evaluation the occurrences in February were utilized. Low wind was defined as wind below $6 \mathrm{~m} / \mathrm{s}$ and Low current was defined as current less than $60 \mathrm{~cm} / \mathrm{s}$. Acceptable limits were available at Site 1 from 10 to 15 February, at Site 2 from 7 to 12 February, and for Sites 3 and 4 from 5 to 10 February.

High current was defined as greater than or equal to $60 \mathrm{~cm} / \mathrm{s}$. Coinciding low wind and high current events were found in July for Sites 1, 3, and 4 covering 
the period 8 to 17 July. Site 2 had an acceptable event from 1 to 6 June. High wind (defined as wind greater than or equal to $10 \mathrm{~m} / \mathrm{s}$ ) and low current events were almost identical for the first three sites and covered the period of 21 to 27 March. Site 4 had a coinciding event during the period of 17 to 22 February.

\section{Oil dispersion patterns}

\subsection{Oil in marine environment}

Factors affecting oil in sea water include wind speed, sea state, currents, and water temperature. These affect the different processes oil goes through once encountering the surface of the water. These processes include: evaporation, emulsification, spreading, solution, sea-air interchange, and sedimentation (Wilson et al. [8]). These processes make up the whole of the term "weathering." The type of oil is also a factor since each type has its own particular mix of hydrocarbons and distillates. For instance, the oil used in these scenarios is Kuwait crude oil and probably has an entirely different molecular make up than oil from Venezuela or the Gulf of Mexico.

\subsection{Oil spill scenarios}

The oil scenarios, ran in OILMAP, were conducted using an arbitrary spill amount of 10,000 bbl (barrels) at four sites. A barrel is equal to 40 gallons or approximately 0.13 tons. The spill was set to last for the duration of one hour and the oil was tracked for a period of up to five days.

In simulations, the oil is left to spread and be acted upon by the environment without human intervention. In reality, this may or may not be the case. Satellite photos show oil slicks in the $\mathrm{SOH}$ and it is not known whether the countries bordering the $\mathrm{SOH}$ have any sort of response plan for a spill of any size. Assuming there is a plan in place by Iran, Oman, or the UAE, the presence of clean up efforts would cause a problem with traffic. At worst, it is estimated that traffic would slow down in the case of an accidental spill.

It is assumed that an explosion would be another story. A ship in distress would cause any available ship to respond to the distress of the crew. Another factor would be discovery as to the cause of the explosion. The presence of mines would preclude clean-up efforts in favor of mine sweeping. Naval operations in the area, along with civilian traffic would be effectively halted until the area could be pronounced clear.

\subsection{Low winds/low currents}

The spread of the oil over the five day period (10-15 Feb) was contained within the $\mathrm{SOH}$ at the tip of the peninsula (Fig. 4). Following initial release, the oil was pushed in the outflow direction and then is shown to stall at the tip of the peninsula after 24 hours (Fig. 4a). Then, after 72 hours (b), the oil is once again caught in an outflow regime. In the last frame (c), the oil has been caught in an inflow type regime. In this case the oil did not go very far or 
make landfall. The Mass Balance Graph (Fig. 4d) shows the rapid initial evaporation that occurs and the exponential decrease in evaporation rate with time. Note that the oil spreads across the $\mathrm{SOH}$ for a significant distance covering the inbound and outbound transit lanes. The transit lanes are in the middle of the oil at the end of the first day and remain among the lanes to conclusion of the simulation time.

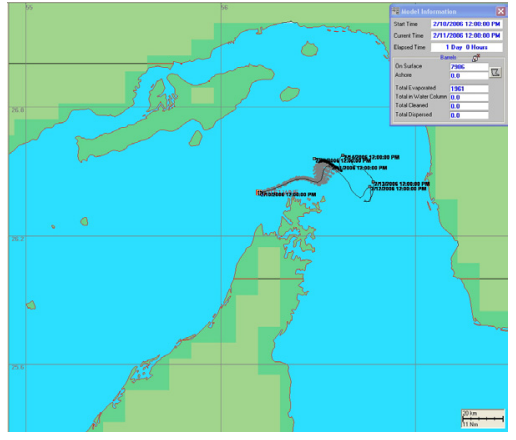

(a)

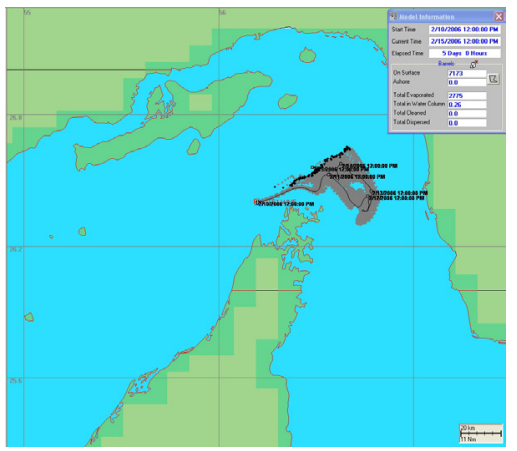

(c)

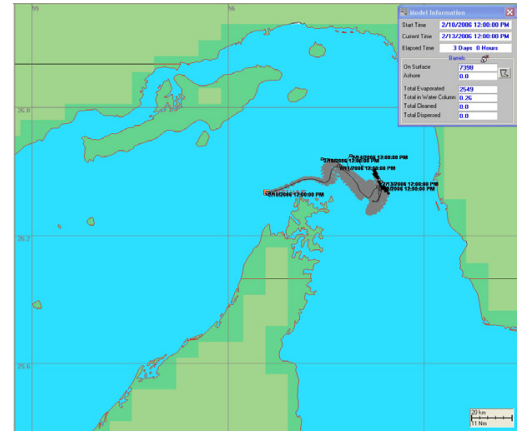

(b)

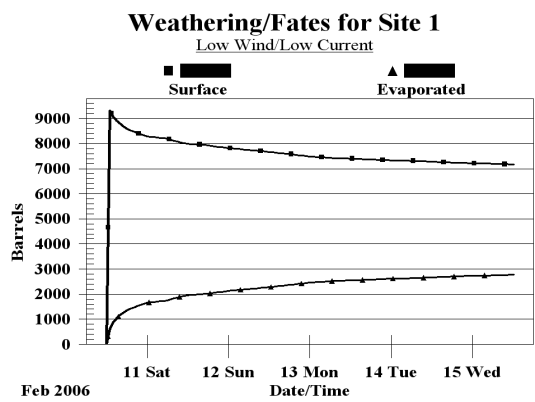

(d)

Figure 4: Oil dispersion at site-1 during low winds/low currents at (a) $24 \mathrm{hr}$, (b) $72 \mathrm{hr}$, and (c) 5 days after the spill and (d) mass balance.

\subsection{High winds/high currents}

In the case of high wind and high current the winds were to the northeast as were the currents. Understand that this is for the release point only. At the two and a half day mark the oil first makes landfall. Upon inspection of the current and wind composite the winds were southwesterly on 22 May and the current was also. However, an anticyclonic eddy was positioned directly to the east of the peninsula. The turning of the oil took place in the first 24 hours when a short period of weakened winds and currents took place. The wind was slightly to the southeast and was enough to turn the oil towards the peninsula. In this case the oil was clear of the transit lanes after the first $24 \mathrm{hr}$. 


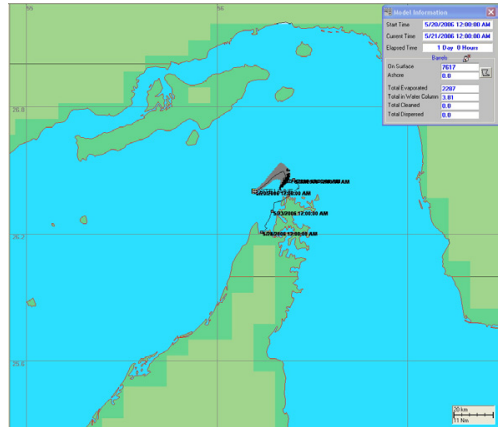

(a)

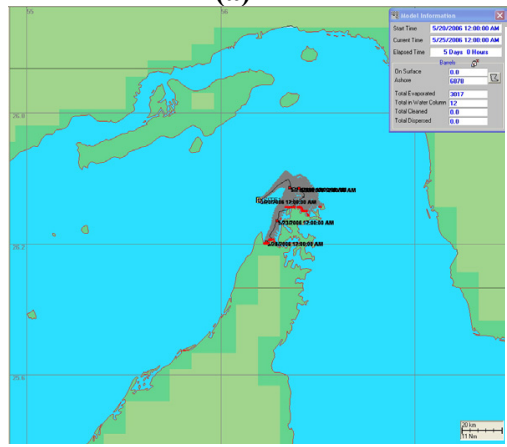

(c)

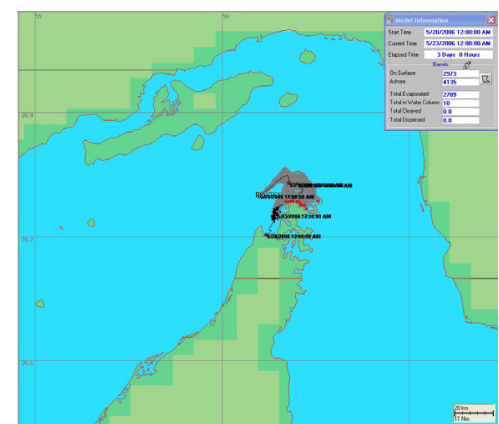

(b)

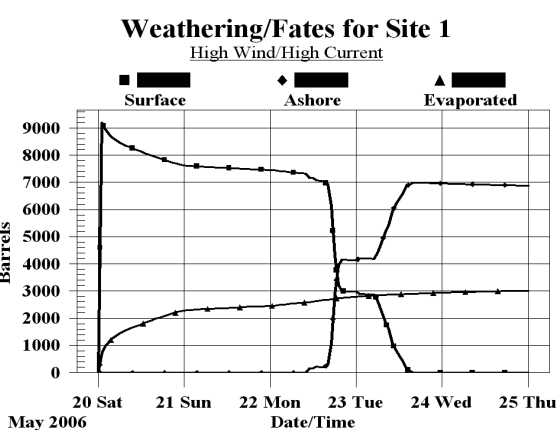

(d)

Figure 5: Oil dispersion at site-1 during high winds/high currents at (a) $24 \mathrm{hr}$, (b) $72 \mathrm{hr}$, and (c) 5 days after the spill and (d) mass balance.

\section{Conclusions}

The Strait of Hormuz is a vital flow point for oil and natural gas that supplies the majority of the world with energy. Any halt to the flow of the resources exiting the Gulf via the SOH is tantamount to a world economic crisis. Once flow is stopped, criticality of the amount of time to transit recommencement cannot be easily estimated. Through the use of sophisticated numerical modeling and data analysis methods, oceanographic and atmospheric models are among the best in the world.

Our study shows conclusively that the tidal forcing, along with variable winds are important for a better prediction of oil slick flow. Without the tidal forcing the oil is unidirectional and lacks the speed change associated with the inflow and outflow regime peaks. Essentially, the utilization of climatology currents is worse than a guess for oil slick prediction. In a reverse estuarine flow such as is found in the Strait of Hormuz, the tidal influence cannot be ignored. Realistic wind forcing is also a necessary feature.

From analyzing the movement oil under the influence of wind and currents we found that winds greater than $5 \mathrm{~m} / \mathrm{s}$ can significantly alter the course of oil slicks. However, if the mean wind is an indication of the overall tendency of the 
strength of winds through the $\mathrm{SOH}(\lesssim 5 \mathrm{~m} / \mathrm{s})$, then it is the current that is the primary driving force for the course of oil spills in the $\mathrm{SOH}$.

\section{References}

[1] Reynolds, R.M., 1993: Physical Oceanography of the Gulf, Strait of Hormuz, and the Gulf of Oman-Results from the Mt Mitchell Expedition. Mar. Pollut. Bull., 27, pp. 35-59.

[2] Kreil, E., 2004: Persian Gulf Oil and Gas Exports Fact Sheet. Energy Information Agency, Department of Energy, Country Analysis Briefs, September. Web site: www.eia.doe.gov/emeu/cabs/pgulf.html.

[3] Hodur, R. M., 1997: The Naval Research Laboratory's Coupled Ocean Atmosphere Mesoscale Prediction System (COAMPS). Mon. Wea. Rev., 125, 1414-1430.

[4] Mellor, G., and T. Yamada, 1982: Development of a turbulence closure model for geophysical fluid problems. Rev. Geophys. Space Phys., 20, 851875.

[5] Sykes, R. I., et al., 2000: PC-SCIPUFF Version 1.3 Technical Documentation. Titan Corporation, A.R.A.P. Report No. 725, December 2000.

[6] Chu, P.C., K. Kyriakidis, and M. Ward, 2006: Two chemical dispersion regimes in tide-dominated San Diego Bay, in: Coastal Environment and Water Quality, Water Res. Publ., 47-68.

[7] Chu, P.C., P. Pauly, and M. Ward, 2006: Wind effect on chemical dispersion in San Andrew Bay, in: Coastal Environment and Water Quality, Water Res. Publ., 69-90.

[8] Wilson, E. B., J. M. Hunt, J. N. Butler, C. D. McAuliffe, R. Patrick, E. A. Pearson, W. D. Garrett, J. M. Teal, F. T. Weiss, R. C. Vetter, and M. H. M. Katsouros, 1975: Petroleum in the Marine Environment: Workshop on Inputs, Fates, and the Effects of Petroleum in the Marine Environment May 21-25, 1973. National Academy of Sciences, Washington D.C. 